\title{
Chinese and Irish professional service firms compared: Linking HPWS, organizational coordination, and firm performance
}

\author{
$\mathrm{Na} \mathrm{Fu}^{\mathrm{a}, *, \text { Janine Bosak}}{ }^{\mathrm{b}}$, Patrick C. Flood ${ }^{\mathrm{b}}$, Qinhai $\mathrm{Ma}^{\mathrm{c}}$ \\ a Trinity Business School, Trinity College Dublin, the University of Dublin, Ireland. \\ b DCU Business School, Dublin City University, Glasnevin, Dublin 9, Ireland \\ ' School of Business Administration, Northeastern University, Shenyang, Liaoning, PR China
}

\section{ARTICLE INFO}

Keywords:

Strategic human resource management

High performance work systems

Firm performance

Organizational coordination

Cultural differences

Professional service firms

\begin{abstract}
A B S T R A C T
Strategic human resource management (SHRM) has an important influence on organizational performance. Previous research has established the positive impact of a specific set SHRM practices - known as high performance work systems (HPWS) - on firm performance. This study furthers our understanding of the performance impact of HPWS by: (a) proposing organizational co-ordination as a unique process-based mediator between HPWS and firm performance and (b) examining the impact of national cultural differences on the relationship between HPWS and organizational performance. Data were collected from 98 Chinese and 93 Irish accounting firms. The findings support the mediating role of organizational coordination in the relationship between HPWS and firm performance. Additionally, we found that the effects of organizational coordination were stronger in the high power distance and collectivistic culture of China than in the low power distance and individualistic culture of Ireland. Implications are discussed.
\end{abstract}

\section{Introduction}

Strategic human resource management is now recognized as a critical factor influencing organizational performance. Researchers and practitioners have engaged in a quest to understand how best to manage employees in order to maximize firm performance (e.g., Arthur, 1994; Becker \& Gerhart, 1996; Chuang \& Liao, 2010; Delery \& Doty, 1996; Fu, Flood, Bosak, Morris, \& O'Regan, 2013; Guthrie, 2001; Huselid, 1995; Takeuchi, Lepak, Wang, \& Takeuchi, 2007). High performance work systems (HPWS) are a means of implementing strategic human resource management (SHRM). They refer to a bundle of practices aimed at enhancing employees' abilities, commitment, and performance (Datta, Guthrie, \& Wright, 2005; Guthrie, 2001). HPWS involve rigorous recruitment, and selection; continuous training and development; developmental performance management; competitive compensation; information sharing and team work (Fu et al., 2017). Existing research has shown that HPWS are positively linked to organizational outcomes such as financial returns (Huselid, 1995); operational productivity (Guthrie, 2001); service quality and efficiency (Gittell, Seidner, \& Wimbush, 2010); organizational innovation (Chen \& Huang,
2009; Collins \& Smith, 2006; Fu, Flood, Bosak, Morris, \& O'Regan, 2015) and organizational social capital (Chuang, Chen, \& Chuang, 2013).

Following extensive research on the impact of HPWS on organizational outcomes, scholars have shifted their attention to understanding how HPWS realize firm outcomes. In so doing, scholars have opened the so-called "black box" in order to identify the mediating mechanisms that exist between HPWS and organizational outcomes (Boxall, Ang, \& Bartram, 2011; Boxall, Guthrie, \& Paauwe, 2016; Wright \& Gardner, 2003). Mediators represent an important linkage mechanism between HPWS and firm performance. Some research has studied the role of employees' attitudes and behaviors in mediating the link between HPWS and firm performance. For example, Boxall et al. (2011) found support for the mediating role of employee empowerment and affective commitment in the relationship between HPWS and employee performance. Sun, Aryee, and Law (2007) found that employees' organizational citizenship behavior mediated the link between HPWS and hotel performance. In addition, studies have further examined team-level processes through which HPWS influence organizational outcomes. For instance, Gittell et al. (2010) found that relational coordination within health and social care teams mediated the relationship between HPWS and patient length of stay and perceived quality of care.

\footnotetext{
Corresponding author.

Email addresses: funa@tcd.ie (N. Fu); janine.bosak@dcu.ie (J. Bosak); patrick.flood@dcu.ie (P.C. Flood); qhma@mail.neu.edu.cn (Q. Ma)
} 
Finally, mediators found at the organizational level include organizational resources (human, social, and organizational capital) (Fu et al., 2017); organizational market orientation (Harris \& Ogbonna, 2001); knowledge management capacity (Chen \& Huang, 2009); strategic orientation (Chow, Teo, \& Chew, 2013); and top management team networks (Collins \& Clark, 2003). These findings have significantly contributed to our understanding of how HPWS influence performance outcomes both theoretically and practically.

This paper extends past research by identifying a crucial organizational factor that links HPWS and firm performance, i.e. organizational coordination. In this study, we use the definition of organizational coordination from Kraut and Streeter (1995) which includes organizational policies and practices such as organizing team meetings regularly, engaging in policies and procedures for coordinating the team's work, and establishing delivery schedules. As a key mechanism whereby organizations process information, i.e. coordination, has been to the fore and centre of organizational theory and design since the 1950s (March \& Simon, 1958). Coordination is an important management strategy which helps organizations to improve their efficiency and effectiveness through the process of matching resources to organizational requirements and managing the interface between diverse units and stakeholders. Understanding the process of organizational, managerial, and information coordination helps to clarify the linkages between HPWS and performance outcomes (Fu et al., 2017). Understanding the role of coordination is especially useful to managers as it enables them to focus their efforts on a variable which is relevant to effective resource utilization. The role of organizational coordination as the mediating mechanism between HPWS and firm performance falls into the category of an intra-management process, which has been deemed to be an important perspective to use when theorizing the relationship between HPWS and firm performance (Boxall et al., 2016).

We test our research model of HPWS and its impact on firm performance (via organizational coordination) in the professional service firm context. In the PSF context human resources are essential to building organizational competitive advantage. Effective organizational coordination is critically required given time pressure and increasing task complexity (Anand, Gardner, \& Morris, 2007). Our study involved professional services firms (PSFs) in two countries (China and Ireland) and used two research design methods (a cross-sectional design in Chinese PSFs and a time-lagged design in Irish PSFs). National cultural differences have been found to influence people's work experience (Hauff, Richter, \& Tressin, 2015). Given such cultural differences, we propose and test the moderating impact of national culture on (a) the relationship between organizational coordination and firm performance; and (b) the overall mediation model (HPWS $\rightarrow$ organizational coordination $\rightarrow$ firm performance). Our research makes several contributions:

First, this study proposes and tests a new process mediator - organizational coordination - which is of particular importance in the professional service context. Secondly, existing research on HPWS and firm performance has been mainly conducted and tested in manufacturing firms while much less research has been conducted in the professional services context. HRM research in the context of PSFs has been very limited. PSFs including accounting, architecture, consulting and law firms (von Nordenflycht, 2010) employ well-educated professionals and are highly dependent on their human resources to provide customized service to clients (Maister, 1993; von Nordenflycht, 2010). They are therefore an appropriate and important context in which to study the performance impact of HRM. Moreover, systematic examination of the performance impact of HPWS has been very limited. Thus, exploring HRM in PSFs helps to fill in these two context gaps. Furthermore, our study enriches HPWS research by including data from PSFs based in two countries: China and Ireland. Doing so helps to extend our understanding of $\mathrm{HR}$ in different national contexts. Lastly, we explored the moderating role of national culture in the relationship between or- ganizational coordination and firm performance as well as in the indirect relationship between HPWS and firm performance via organizational coordination. Our study thus answers a call for (a) research on cultural fit in HRM research (Budhwar \& Sparrow, 2002; Farndale \& Sanders, 2017) and (b) understanding and leveraging "similarities and differences in an ever-more increasingly globalized and interdependent world" (Gelfand, Aycan, Erez, \& Leung, 2017: 525).

\section{Theoretical background and hypotheses}

\subsection{High performance work systems and the resource-based view of the firm}

High performance work systems (HPWS) are composed of HR practices that build human capital and are designed to enhance employees' knowledge, skills, commitment, and performance so that employees become a source of sustainable competitive advantage (e.g., Datta et al., 2005). Their impact on organizational performance has been widely studied in manufacturing firms where HPWS are found to positively relate to firms' financial returns (Guthrie, 2001; Huselid, 1995); productivity (Guthrie, 2001); efficiency and flexibility (Evans \& Davis, 2005); and revenue growth (Fu et al., 2017). The effect of HRM on performance has also been found in service industries such as banks (Batt, 2002), hair and beauty salons, restaurants and cafes (Chuang \& Liao, 2010), and hotels (Sun et al., 2007). The rationale for the performance impact of HPWS is that HPWS help organizations to develop valuable human resources which, utilized effectively, enable them to succeed. According to the resource-based view of firms, organizations with highly valuable human resources are more likely to achieve high performance (Barney, 1991). Human resource management practices themselves are not a resource for firms to gain success but the human resource capability which is built up through the HRM practices is an intangible asset which can be leveraged (Jiang, Lepak, Hu, \& Baer, 2012). Such human resources enable organizations to coordinate tasks, projects and people more effectively.

\subsection{Organizational coordination and organizational information processing}

Coordination has been regarded "at the centre of organization theory ever since March and Simon (1958) suggested that work in organizations could be coordinated" (cited in Faraj \& Xiao, 2006: 155). Historically, coordination received considerable interest in the eighteenth century where the railroads became a new form of organization due to their large scale use of labor and the complexity of project and labor management involved (Chandler, 1962). With the introduction of information technology, for example internet access and software use, into work and life, tasks have become more complex. This has attracted increased focus on effective coordination. Malone and Crowston (1994) developed coordination theory and defined coordination as "managing dependencies between activities" (page 90). Coordination theory is based on a variety of different disciplines including computer science, organization theory, management science, economics, and psychology and can be applied to organizational design and information processing (Malone, 1988). Using coordination theory, Crowston (1997) analyzed a software change process in a large mini-computer manufacturer. To fix a software bug problem, software engineers, marketing engineers, and managers worked together on the issues of task assignment, resource sharing, and managing dependencies between modules of source code, a process of coordination through which the software bug problem is solved.

More recently, Faraj and Xiao (2006) defined coordination as a "temporally unfolding and contextualized process of input regulation and interaction articulation to realize a collective performance" (page 1157). The efficiency of such a process depends on coordination mech- 
anisms which "are the organizational arrangements that allow individuals to realize a collective performance" (Okhuysen \& Bechky, 2009: 472). According to Mintzberg (1979: 3), coordination mechanisms are "the most basic elements of structure" in organizations. Galbraith (1974) argued that organizations need to build their information processing capacity in order to enhance organizational performance. He suggested various coordination mechanisms that organizations use to adapt to information processing load including rules, schedules, and project teams. Over three decades later, Okhuysen and Bechky (2009) conducted a systematic review on coordination in organizations. They found that coordination mechanisms (such as routines, meetings, plans, and schedules) significantly influenced the work of organizations through three integrative conditions: accountability, predictability, and common understanding of tasks and projects. In this study, organizational coordination refers to organizational policies and routine practices such as organizing team meetings regularly, engaging in policies and procedures for coordinating the team's work, and establishing delivery schedules (Kraut \& Streeter, 1995). The quality of organizational coordination sends coherent and consistent messages to employees regarding effective management of the organization.

\subsection{Linking HPWS to organizational coordination}

HPWS help firms improve organizational coordination by developing a high level of human capital, which enables organizations to process information more efficiently and effectively (Fu et al., 2017; Guthrie, 2001). Based on the AMO framework underpinning SHRM, human resource practices develop employees' ability (A), motivation (M), and opportunity to express their efforts at work (O). This framework has been widely used to explain how HPWS influence individual and organizational outcomes (Armstrong et al., 2010; Boxall et al., 2016; Fu et al., 2013). It can also be used to explain the link between HPWS and organizational coordination in PSFs. With creative and highly skilled staff, PSFs need to maximize the utilization rate of staff and be capable of deploying team members swiftly. PSFs attract, develop, and retain talent through HPWS using extensive training, performance management, and information sharing practices. For example, PSFs attempt to recruit staff from top institutions whose graduates have potentially better learning capability (Hitt, Bierman, Shimizu, \& Kochhar, 2001) and invest in training and development to further build their human capital. In addition, HPWS improve employees' motivation to work in a team through participation, internal promotion, and information sharing practices. When staff are highly motivated, they are more committed to collaborative tasks coordinated within the organization. HPWS also helps to build a supportive culture and work climate (Ferris et al., 1998). When the work climate is positive, staff in PSFs are more likely to co-operatively focus their work effort, thus facilitating organizational coordination. Therefore, we anticipate a positive link between HPWS and organizational coordination in PSFs.

Hypothesis 1 . HPWS will be positively linked to organizational coordination in PSFs.

\subsection{Linking organizational coordination to organizational performance}

According to Okhuysen and Bechky (2009), organizational coordination improves firm performance via three mechanisms: accountability, predictability, and the establishment of a common understanding among members (i.e. shared mindset). Accountability is especially important among the key actors who are responsible for specific task elements. Given clear task assignment and accountability, organization staff have a better understanding of their jobs and the responsibilities of others. Predictability enables interdependent actors or departments to know the timeline of the different tasks and activities. Thus, they can anticipate subsequent tasks and plan for future work. Finally, the establishment of a common understanding (shared mental model) among different members, teams, and departments allows individuals to appreciate how their work fits within a whole project. In PSFs, coordination and communication benefits firm performance through combining and recombining individual knowledge into group level knowledge and organizational knowledge (Nahapiet \& Ghoshal, 1998). In PSFs, most of the work is conducted through teams (Gardner et al., 2012). Professional staff need to work together in order to accomplish projects especially during peak periods, which for accounting firms are January to April and August to October yearly, when work load sharply increases. At these times, organizational coordination becomes critical and enables employees to update their work and exchange ideas on how work should be done, thereby enabling the effectiveness and efficiency of project work. PSFs are usually team-based or project-based, meaning a large project may involve a number of teams in different functions. To successfully complete projects, organizational coordination is critically necessary to the process of team member selection and team formation, organizing meetings, and ensuring that all teams are following consistent policy and procedure. In PSFs, such coordination promotes knowledge exchange and sharing within and between teams. It also improves the transparency of both teams' work processes and progress. It provides the foundation for timely, frequent, and accurate communication, and benefits firm performance through the successful completion of clients' projects. Therefore, we anticipate a positive impact of organizational coordination on firm performance in PSFs.

As shown in the above review and analysis, HPWS are hypothesized to have a positive impact on organizational coordination and we anticipate that organizational coordination is positively related to firm performance. HPWS help organizations to build valuable human capital and is supportive of organizational coordination mechanisms oriented towards achieving organizational goals, and achieving organizational performance. Hence, we hypothesize that the relationship between HPWS and firm performance is mediated by organizational coordination:

Hypothesis 2. Organizational coordination mediates the link between HPWS and firm performance in PSFs.

\subsection{The impact of national culture}

National culture shapes people's mindsets, values, and the way they work. According to Hofstede, Hofstede, and Minkov (2010), there are four dimensions of relevance in each national culture. These dimensions are: Power distance (PDI), individualism versus collectivism (IDV), masculinity versus femininity (MAS), and uncertainty avoidance (UAI). A fifth dimension labelled long term-orientation (LTO) was added by Hofstede (1991) based on the research from Hofstede and Bond (1988). Fig. 1 illustrates how China and Ireland compare on the five cultural dimensions.

In comparison to Ireland, China has higher scores on power distance $(80 \mathrm{v} 28)$ and long-term orientation $(118 \mathrm{v} 43)$ and it scores higher on collectivism $(70 \mathrm{v} 20)$. The scores suggest pronounced cultural differences between the countries of China and Ireland. Chinese culture is more collective, depending on relationships (guanxi) while the Irish culture is relatively more individualistic, and dependent on rule allocation mechanisms-a feature of a low-context culture. The context-based approach used to examine national cultural differences was developed by Hall (1976) who distinguished high-context from low-context cultures. According to Hall (1976: 101), high-context transactions "feature pre-programmed information that is in the receiver and in the setting, with only minimal information in the transmitted message" and low-context transactions "are the reverse" where most of information is in the explicit code and format. According to his model, China is an example of a high-context culture in which people's com- 


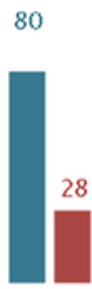

PDI
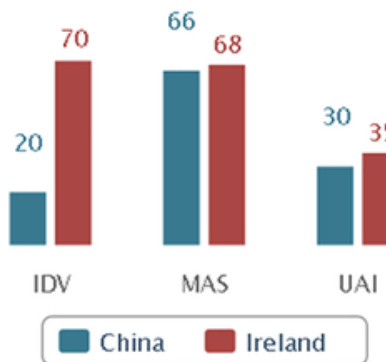

66

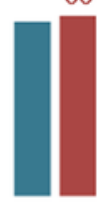

30

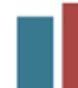

A

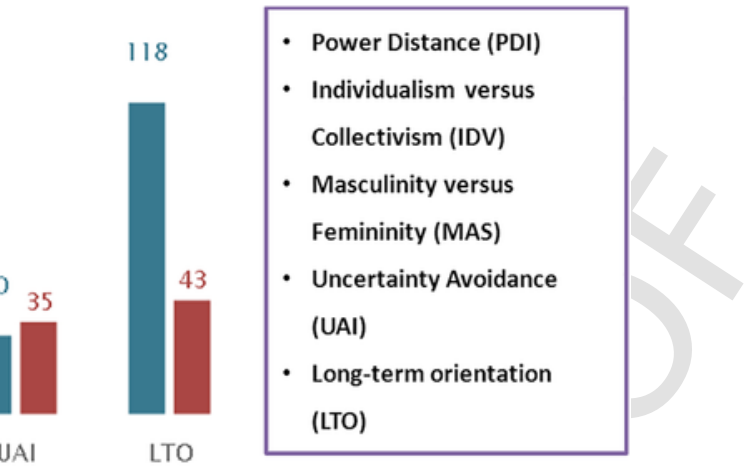

Source: www.geert-hofstede.com

Fig. 1. National culture comparison between China and Ireland.

munication is very context-based where implicit and complex information is shared among members (Kittler, Rygl, \& Mackinnon, 2011). Face-to-face meetings and interactions are key in China to establishing trust and are the common, standardized format to communicate among members. In contrast, Ireland is an example of a relatively low-context culture in which people are more likely to use explicit communication via codified knowledge (Croucher et al., 2012).

Given the above cultural differences between China and Ireland, the performance impact of organizational coordination in PSFs may differ. Members' relationships are more important in Chinese PSFs than in Irish PSFs. In Chinese PFS, given standardized organizational coordination mechanisms, members are more likely to build valuable relationships via frequent meetings and networking events to coordinate their work. In Irish PSFs, codified knowledge is more important. When organizations engage in a codified project management process, members are more likely to follow established rules. Therefore, we expect that the performance impact of organizational coordination will be stronger in Chinese PSFs than in Irish PSFs. Given the importance of relationships and the use of complex context-based communication in Chinese PSFs, we also expect that the strength of the mediation model of HPWS and firm performance via organizational coordination is stronger in Chinese PSFs than in Irish PSFs. In other words, HPWS are more likely to influence firm performance via organizational coordination in Chinese PSFs than in Irish PSFs.

Hypothesis 3. National culture moderates the link between organizational coordination and firm performance such that the link will be stronger for Chinese compared to Irish PSFs.

Hypothesis 4. National culture moderates the mediation model of HPWS and firm performance via organizational coordination such that the mediating effect of organizational coordination will be stronger for Chinese PSFs compared to Irish PSFs.

Fig. 2 presents our theoretical model.

\section{Research methodology}

To test our proposed research model, we collected data from PSFs in China and Ireland. The Chinese sample included 98 Chinese accounting firms. The Irish sample included 93 Irish accounting firms. All studied variables were measured using existing published and valid scales including the measures of HPWS, organizational coordination, and organizational performance. We employed a cross-sectional research design in the Chinese sample and a time-lagged design in the Irish sample. We originally intended to use time-lagged design in both samples. However, we were only provided access to Chinese PSFs at one point in time only. This led ultimately to the adoption of a cross-sectional research design in gathering the Chinese data. Combining the data from both samples allow us to test the generalizability of our proposed research model.

\subsection{Procedure and sample profile}

To obtain access to Chinese accounting firms, one author approached the Liaoning Institute of Certified Public Accountants (LICPA) which manages 378 accounting firms based in the Liaoning Province in China. Following communication with LICPA, we were provided with the opportunity to collect data during a training event held by LICPA. All accounting firms were invited to attend this training event. Hard copy surveys were distributed to managers from 120 accounting firms who attended the training course (participation rate at institutional level: $32 \%)$. In total, 112 surveys were returned with 14 surveys yielding incomplete data, which resulted in 98 valid surveys (response rate of $81.67 \%$ ) representing 98 accounting firms. This high response rate is comparable to that of other studies using similar survey distribution methods (e.g., 78\% in Gardner et al., 2012). Our survey instrument was developed in English. All variables used in this study were adapted from established scales. They were then translated into Chinese. To ensure the consistency of measurement meaning in translation, we followed the back-translation procedure recommended by Brislin (1980).

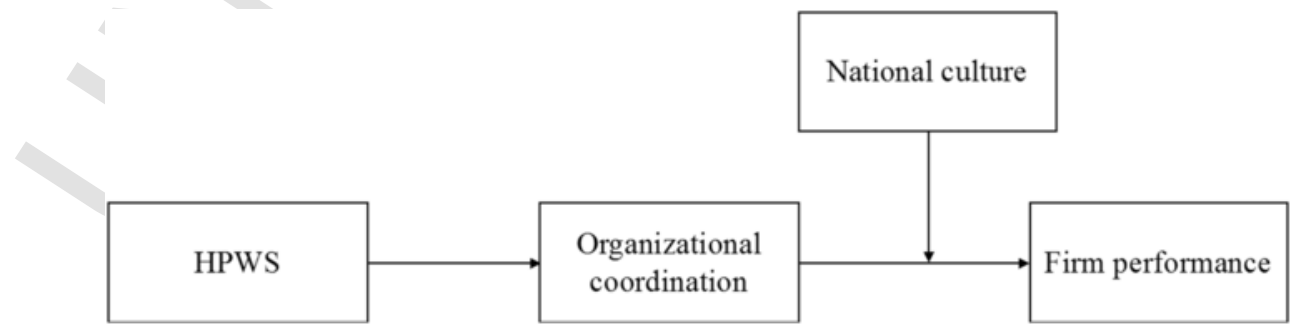

Fig. 2. Conceptual model.Note: HPWS = high performance work systems. 
First, the survey was translated from English to Chinese by two Chinese professional translators. A bilingual researcher in the business management field checked the Chinese version of the survey and translated the survey into English. Finally, a native English speaker who has an academic background in management checked the back-translated survey and confirmed evidence of consistency.

In collecting data from Irish accounting firms, we adopted a time-lagged design in order to reduce the limitations of cross-sectional design where common method bias may occur. Data collection occurred at two-time points twelve months apart. At Time 1, a survey measuring HPWS and organizational coordination was sent out to managing partners and HR managers (or the senior partners if there were no HR managers) in 274 accounting firms based in Ireland. To avoid single-rater bias (Gerhart, Wright, McMahan, \& Snell, 2000), we sent two surveys to each firm. In total, we received completed surveys from 120 firms (45.98\%), with 72 firms returning two completed surveys and 48 firms returning one completed survey. At Time 2 (one year later), a survey measuring only firm performance, was sent out to the same 120 firms. In total, 93 firms (78\%) returned completed surveys, with 33 firms returning two completed surveys and 60 firms returning one completed survey. We then combined the data collected at Time 1 and Time 2, which resulted in data collected from 93 firms across both time points. We used this matched data for the subsequent data analysis. To check the representativeness of the sample, we conducted a series of comparison analyses using analysis of variance (ANOVA). No significant differences were found between respondents and non-respondents at T2; and between early respondents and late respondents at both $\mathrm{T} 1$ and $\mathrm{T} 2$ regarding demographic variables such as participant gender, age, education, and job tenure. In addition, there was no significant difference in terms of revenue, size, age and partnership structure between those firms returning two surveys and firms returning one survey at $\mathrm{T} 1$ and $\mathrm{T} 2$. Therefore, we used the responses from 93 firms aggregating the matched pairs data to the firm level and combining this with the single response firm data. Support for the aggregation was based on high inter-rater agreement and reliability where: (i) Rwgs were all above the threshold value of 0.70; (ii) ICC(1) values were all above the threshold value of 0.12 ; and (iii) ICC(2) values were all above the threshold value of. 60 .

Among the respondents, 79\% of respondents were Managing Partners or Partners, $14 \%$ of respondents were HR Manager/Directors, and $7 \%$ of respondents were experienced professional staff who had a good knowledge of their organizations; $71 \%$ of respondents were males. The average age of respondents was 50 years old $(S D=9)$ and the average tenure in the firm was 18 years $(S D=8)$.

\subsection{Measures}

\subsubsection{HPWS}

Sixteen items were adopted from multiple sources including Huselid (1995), Guthrie et al. (2009) and Collins and Smith (2006), to fit the professional service context. These items cover the main SHRM practices and include rigorous recruitment via employee test and structured interview, continuous training and development, developmental performance management, competitive compensation, and employee participation. We asked the respondents to provide information on the proportion of professional staff who were covered by each HR practice (ranging from $0 \%$ to 100\%). Example practices included: "an employment test (e.g. skills tests) prior to hiring", "continuous training, e.g., continuous professional development", "structured mentoring", and "self-directed work teams". The HPWS index was created by averaging across all items. It showed good internal consistency reliability (Cronbach's $\alpha=0.83$ ).

\subsubsection{Organizational coordination}

Seven items were adopted from Kraut and Streeter (1995) to measure organizational coordination. Respondents were asked to what extent their organizations engaged in organizational coordination activities. Example activities included: "regularly scheduled team meetings", "formal policies and procedures for coordinating the team's work", and "project milestones and delivery schedules". Respondents answered on a seven-point Likert scale ranging from $1=$ small extent to $7=$ great extent. Internal consistency reliability of the coordination scale was 0.90 .

\subsubsection{Firm performance}

Firm performance was assessed using self-report comparative measures. Seven items were adopted from Delaney and Huselid (1996) to measure the firm's relative organizational performance. Respondents compared their organization's performance relative to competitors in relation to their "development of new services" and "ability to attract essential employees" using a Likert scale ranging from $1=$ much worse to 7 = much better. The subjective measures of company performance (relative to competitors) are positively associated with the objective measures. Empirically, Wall et al. (2004) found that subjective and objective measures of company performance were positively associated at 0.52 . Despite the criticism, many empirical studies adopt the use of self-report performance measure due to the difficulty of collecting objective firm performance (Chuang \& Liao, 2010; Delaney \& Huselid, 1996; Liao, Toya, Lepak, \& Hong, 2009; Sun et al., 2007). Internal consistency reliability of the firm performance scale was $\alpha=0.86$.

\subsubsection{Control variables}

We controlled for firm characteristics such as firm age and firm size which were operationalized as their natural logs. Controlling for firm age and size was necessary because of their possible association with the adoption of HPWS, organizational coordination, and firm performance. For example, larger firms might have more formal organizational coordination process or policies in place than smaller firms. The variable 'national culture' was operationalized by using scores from Hofstede et al. (2010). In particular, we used two significantly distinct aspects, i.e. power distance and collectivism. China has higher scores on power distance $(80 \mathrm{v} 28)$ while it scores lower on individualism $(20 \mathrm{v} 70)$ compared to Ireland. National culture was used as a control variable for testing Hypotheses 1 and 2 while as a moderator in testing the moderating effect of national culture in the relationship between organizational coordination and firm performance in Hypotheses 3 and 4.

\section{Results}

Table 1 shows the descriptive statistics including means, standard deviations, correlations between variables and reliability coefficients. The results of the regression analysis are shown in Table 2.

Hypothesis 1 proposed a positive link between HPWS and organizational coordination. The results in Table 2 (Model 1.2) indicate that HPWS were positively and significantly linked to organizational coordination $(\beta=0.36, p<.001$ ) after controlling for firm age, firm size and culture. Therefore, Hypothesis 1 was supported.

Hypothesis 2 proposed that organizational coordination would mediate the link between HPWS and firm performance. The mediation test followed the four conditions described by Baron and Kenny (1986). These are: (1) that the independent variable is directly related to the dependent variable (HPWS $\rightarrow$ firm performance); (2) that the independent variable should be related to the mediator (HPWS $\rightarrow$ organizational coordination); (3) that the mediator should be related to the dependent variable (organizational coordination $\rightarrow$ firm performance); and (4) that the direct relationship between the independent and de- 
Table 1

Descriptive statistics.

\begin{tabular}{|c|c|c|c|c|c|c|c|}
\hline Variables & Mean & S.D. & 1 & 2 & 3 & 4 & 5 \\
\hline 1. Firm performance & 5.25 & 0.77 & $(0.83)$ & & & & \\
\hline 2. Organizational coordination & 45.16 & 23.71 & $0.25^{* *}$ & $(0.90)$ & & & \\
\hline 3. HPWS & 4.96 & 1.07 & $0.44^{* *}$ & $0.36^{* * *}$ & $(0.86)$ & & \\
\hline 4. Firm age & 2.54 & 0.84 & 0.05 & 0.03 & 0.03 & & \\
\hline 5. Firm size & 2.99 & 0.85 & $0.16^{*}$ & $0.18^{*}$ & 0.13 & $0.27^{* *}$ & \\
\hline 6. Culture ${ }^{\mathrm{a}}$ & 0.54 & 0.5 & 0.05 & 0.03 & -0.02 & $-0.41 * *$ & -0.01 \\
\hline
\end{tabular}

Note: $N=161$ (listwise) ${ }^{* *} p<.01,{ }^{*} p<.05$ (two-tailed tests). HPWS $=$ high performance work systems; ${ }^{\text {a }} 1=$ China, $0=$ Ireland. Figures in parentheses are Cronbach's alphas.

Table 2

Regression results.

\begin{tabular}{|c|c|c|c|c|c|c|c|}
\hline \multirow[t]{2}{*}{ Variables } & \multicolumn{2}{|c|}{ Organizational coordination } & \multicolumn{2}{|c|}{ Firm performance } & \multirow[b]{2}{*}{ Model 2.3} & \multirow[b]{2}{*}{ Model 2.4} & \multirow[b]{2}{*}{ Model 2.5} \\
\hline & Model 1.1 & Model 1.2 & Model 2.1 & Model 2.2 & & & \\
\hline \multicolumn{8}{|l|}{ Controls } \\
\hline Firm age & -0.04 & -0.03 & 0.04 & 0.05 & 0.04 & 0.00 & 0.00 \\
\hline Firm size & $0.23^{* * *}$ & $0.15^{*}$ & $0.17^{* *}$ & 0.12 & 0.10 & 0.12 & 0.12 \\
\hline National culture ${ }^{\mathrm{a}}$ & -0.03 & -0.04 & 0.04 & 0.03 & 0.02 & & \\
\hline \multicolumn{8}{|l|}{ Predictor } \\
\hline HPWS & & $0.36^{* * *}$ & & $0.21^{* *}$ & 0.06 & 0.07 & 0.07 \\
\hline \multicolumn{8}{|l|}{ Mediator } \\
\hline Organizational coordination & & & & & $0.40^{* * *}$ & $0.35^{* * * *}$ & $0.35^{* * * *}$ \\
\hline \multicolumn{8}{|l|}{ Moderator } \\
\hline National culture ${ }^{\mathrm{a}}$ & & & & & & 0.02 & 0.02 \\
\hline \multicolumn{8}{|l|}{ Interaction term } \\
\hline Organizational coordination $\times$ national culture ${ }^{\mathrm{a}}$ & & & & & & $0.42^{* * *}$ & $0.42^{* * * *}$ \\
\hline Adjusted $\mathrm{R}^{2}$ & 0.04 & 0.16 & 0.02 & 0.06 & 0.19 & 0.27 & 0.27 \\
\hline$\Delta \mathrm{R}^{2}$ & 0.05 & 0.12 & 0.04 & 0.04 & 0.14 & 0.08 & 0.08 \\
\hline$\Delta \mathrm{F}$ & $3.78^{*}$ & $29.95^{* * *}$ & 1.98 & $7.22^{* *}$ & $27.41^{* * *}$ & $17.45^{* * * *}$ & $17.45^{* * *}$ \\
\hline
\end{tabular}

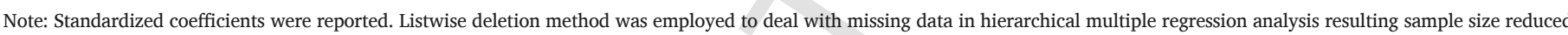
to 161 .

a It was presented by power distance all models except for Model 2.5 where collectivism was used.

**** $p<.001$.

** $p<.01$.

$* p<.05$ (two-tailed tests).

pendent variables should become non-significant (full mediation) or weaker (partial mediation) when accounting for the effect of the mediator. The results in Table 2 (Model 2.2) show that HPWS were positively linked to firm performance $(\beta=0.21, p<.01)$ supporting the first condition. Regarding the second condition, these were met as support was found for Hypothesis 1 in relation to the positive impact of HPWS on organizational coordination. The third condition was met based on the finding that organizational coordination was significantly and positively linked to firm performance $(\beta=0.40, p<.001)$ after controlling for firm age, firm size and country as well as HPWS. Models 2.2 and 2.4 showed that the coefficients for HPWS on firm performance became non-significant when organizational coordination was included in the model (from $\beta=0.21, p<.01$ to $\beta=0.06$, n.s.), satisfying the last condition. We used a bootstrapping test to further examine the significance of the mediation (Hayes, 2009). Based on 5000 bootstrapping samples, the $95 \%$ of confidence interval for the mediating effect was between 0.0021 and 0.0072 , thus excluding 0 . Our results showed that organizational coordination mediated the relationship between HPWS and firm performance. Therefore, Hypothesis 2 was supported.

Hypothesis 3 proposed that national culture would moderate the link between organizational coordination and firm performance such that the link would be stronger in the high power distance and collectivistic culture of China compared to the low power distance and individualistic culture of Ireland. In order to examine the moderation model, we carried out hierarchical moderated regression analysis using 'national culture' as a moderator in the link between organizational coordination and firm performance. Specifically, we carried out the following three steps: We firstly entered the control variables (Model 2.1 in Table 2), then we entered the predictor, organizational coordination
(Model 2.3 in Table 2), and, finally, we entered the moderator (national culture) and the interaction term into the regression equation (Model 2.4 in Table 2). All variables were standardized to avoid multicollinearity (Aiken \& West, 1991). As shown in Models 2.3 and 2.4, the coefficient for the interaction term of organizational coordination and national culture was significant in predicting the relative organizational performance $(\beta=0.29, p<.001)$ for both power distance and collectivism. Figs. 3 and 4 plotted the interaction. It indicated that the link between organizational coordination and firm performance was stronger in the high power distance and collectivistic culture of China than in the low power distance and individualistic culture of Ireland. We then examined the moderating effect by conducting the simple slope analysis. The results provided further support for Hypothesis 3 (Gradient of simple slope $=0.49, t=6.41, p<.001$ in the high power distance and collectivistic culture of China; Gradient of simple slope $=0.05, t=0.63$, n.s.) in the low power distance and individualistic culture of Ireland. Therefore, Hypothesis 3 was supported.

Hypothesis 4 proposed a moderated mediation model whereby the strength of the mediational model, i.e. the relationship between HPWS and firm performance mediated by organizational coordination, would be moderated by national culture. Put simply, the mediating effect of organizational coordination would be stronger in the high power distance and collectivistic culture of China than in the low power distance and individualistic culture of Ireland. To assess moderated mediation (Muller, Judd, \& Yzerbyt, 2005; Preacher, Rucker, \& Hayes, 2007), we examined five conditions: (1) significant effects of the independent variable on the dependent variable; (2) significant interactions between the independent variable and the moderator in predicting mediator; (3) significant effects of the mediator on dependent variable; (4) signifi- 


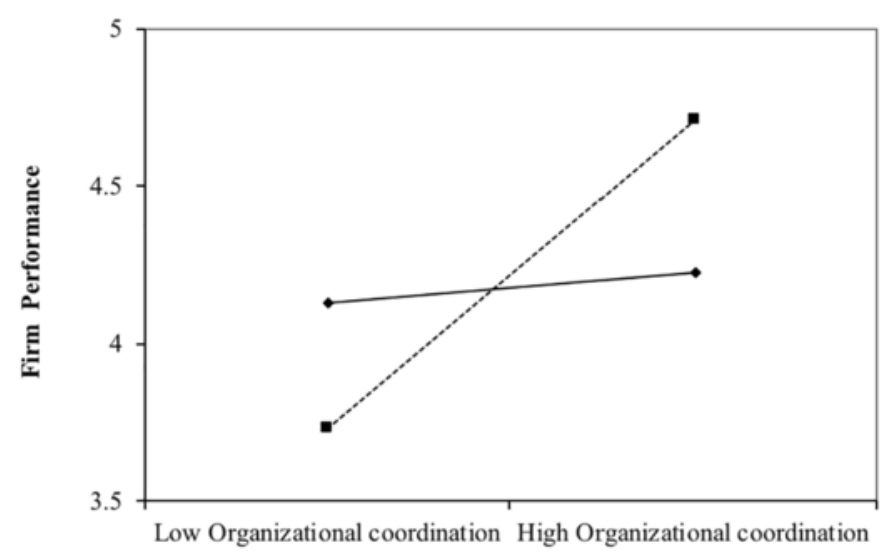

Fig. 3. Interactions between organizational coordination and national culture (power difference) on firm performance.
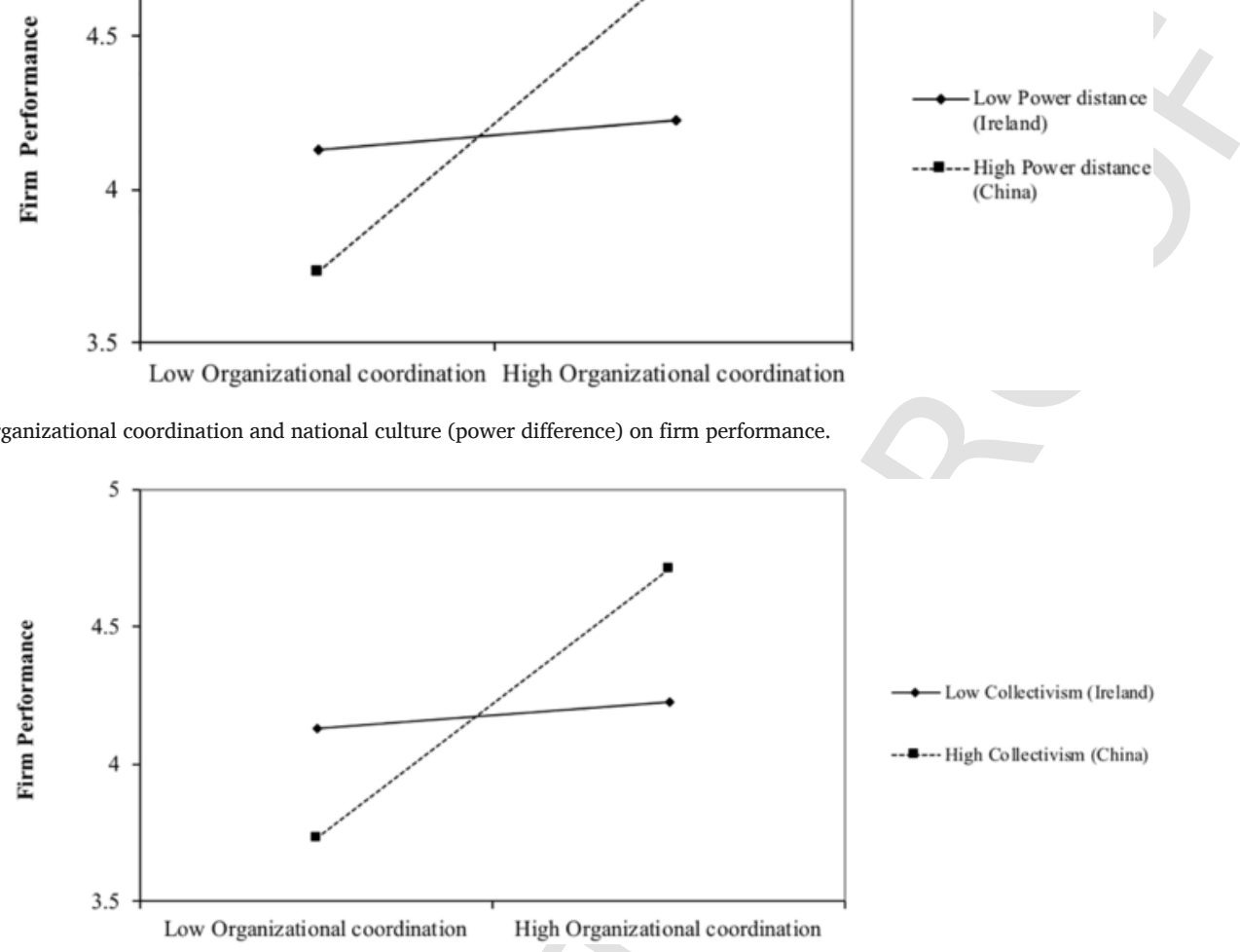

Fig. 4. Interactions between organizational coordination and national culture (collectivism) on firm performance.

cant interaction between the mediator and moderator variables in predicting the dependent variable; and (5) a different conditional indirect effect of the independent variable on the dependent variable, via the mediator, across low and high levels of the moderator. Moderated mediation is assessed through the last condition when the conditional indirect effect differs in strength across low and high levels of the moderator (Preacher et al., 2007). Support was found for Hypotheses 1 to 3 satisfying the first four conditions. To test the 5th condition regarding the differential indirect effect of HPWS via organizational coordination on firm performance for China compared to Ireland, we used Hayes' (2013) PROCESS 3.0 using 5000 bootstrap samples. The results revealed that the indirect effects were (0.0074 in Chinese PSFs; 0.0010 in Irish PSFs) and the $95 \%$ confidence intervals for the indirect effects were [0.0039, 0.0119] in Chinese PSFs and [-0.0011, 0.0037] in Irish PSFs. Overall, the index of moderated mediation (difference between conditional indirect effects) was 0.0064 with a $95 \%$ confidence interval of $[0.0024$, 0.0111]. Therefore, Hypothesis 4 was supported.

\section{Findings and discussion}

The aim of this study was to understand how HPWS influence firm performance cross-culturally by examining the links between HPWS, organizational coordination, and firm performance in the professional service context. Our research integrated human capital theory (Becker, 1964), organizational coordination theory (Faraj \& Xiao, 2006; Malone \& Crowston, 1994; Okhuysen \& Bechky, 2009) and the organizational information processing model (Galbraith, 1974). Building on these theoretical frameworks, we proposed and tested a moderated mediation model where national culture moderated the mediation model linking HPWS and firm performance via organizational coordination. Using data collected from PSF samples in two countries, and different re- search design methods, we found support for the mediating role of organizational coordination in the relationship between HPWS and firm performance. In addition, we found that the performance impact of organizational coordination and the mediating effect of organizational coordination, in the relationship between HPWS and firm performance, was stronger in Chinese PSFs than in Irish PSFs. These findings have important implications for both theory and practice. Below, we discuss these implications along with new directions for research.

\subsection{Scholarly implications}

Our findings suggest that the performance impact of HPWS in PSFs occurs in two steps: (1) HPWS increase organizational coordination; and (2) organizational coordination increases firm performance. In other words, organizational coordination mediates the link between HPWS and firm performance. The identification and support for organizational coordination as an underlying mechanism between HPWS and firm performance extends our knowledge of the "black box" problem in HRM research. To date, researchers investigating the link between HPWS and firm performance have largely focused on employee attitudes and behaviors as underlying mediators of this link. For example, Boxall et al. (2011) found that both employee empowerment and employee commitment mediated the link between HPWS and employee performance. Barling et al. (2003) and Piening, Baluch, and Salge (2013) both identified employee job satisfaction as a mediator in the relationship between HPWS and individual and unit outcomes. Other mediators identified between HPWS and organizational outcomes included social climate (Collins \& Smith, 2006), social exchange (Takeuchi et al., 2007) and perceived organizational support (Liao et al., 2009). In terms of employee behaviors, Sun et al. (2007) investigated employees' organizational citizenship behavior as a mediator in 
the HPWS - organizational performance link. Some studies have found strategic factors that link SHRM and firm performance (Chen \& Huang, 2009; Fu et al., 2017; Harris \& Ogbonna, 2001). In more detail, Chen and Huang (2009) examined the mediating role of organizational knowledge management capability (including knowledge acquisition, sharing, combination and application) in the link between SHRM and organizational innovative performance. Fu et al. (2017) identified two sets of mediators, i.e. organizational resources and the uses of resources, in the relationship between HPWS and firm performance. The mediation found in the latter study is mostly partial, suggesting the existence of other mediators. Harris and Ogbonna (2001) found that SHRM increased organizational market orientation which, in turn, increased organizational performance. Extending these studies, the present study found that a managerial process, organizational coordination, acts as a mediator between HPWS and firm performance. By doing so, this study provides additional insights into how HPWS influence firm performance. To advance research on HPWS, research has focussed almost exclusively on mediators between HPWS and firm performance that represent rather stable individual (e.g. human capital) or organizational (e.g. knowledge management capability) variables and overlooked organizational systems, processes, and routines which are very important in organizational management. By focusing on organizational coordination, which has been the centre of organization theory and design since the 1950s (March \& Simon, 1958), this study provides researchers in HR and organizational theory with important new insights on the key linkages between HR, organizational coordination, and firm performance. In addition, this study provides companies with new insights into system-based organizational processes. Implementing these insights allows them to put in place HRM policies and procedures in order to better coordinate work processes. Effective coordination is increasingly important for organizations that are facing increasing volatile demands and uncertainty. In fact, future research needs to adopt a multilevel view, combining macro and micro levels in order to better understand how macro level variables influence micro level ones and vice versa.

Second, we found support for the performance impact of HPWS and organizational coordination in the professional service context. In doing so, this study fills a context gap as there is a paucity of studies which examine the role of HRM in the PSF context. Existing research on HPWS and firm performance has been widely conducted in manufacturing firms including steel companies (Arthur, 1994; Datta et al., 2005; MacDuffie, 1995) and general service contexts, such as banks (Liao et al., 2009); call centres (Batt, 2002); and hospitals (Gittell et al., 2010). Research on how HPWS influence firm performance in a highly human resource dependent context, such as PSFs, has however been scarce. In relation to the PSF literature, many scholars have looked at varied aspects of PSFs. They include the definition of PSFs (von Nordenflycht, 2010), ownership (von Nordenflycht, 2007); business model transformation (Greenwood et al., 1990), promotion models (Morris \& Pinnington, 1998), and knowledge management (Anand et al., 2007). However, the role of HPWS in enhancing PSF performance has been largely overlooked. By examining how HPWS influence firm performance in PSFs this study provides insights into HRM in PSFs which contributes to a better understanding of the HRM in the professional service context as well as the strategic management of PSFs via the people management perspective (Skjølsvik, Pemer, \& Løwendahl, 2017).

Third, our study enriches HPWS research by employing a varied and rigorous research design in two countries. The design included a single respondent, cross-sectional design for the data collection in Chinese PSFs and a time-lagged design with both single and paired respondents for data collection in Irish PSFs. Varied design methods helped us to generalize the research findings. Overall, we found consistent findings regarding the mediation role of organizational coordination in the relationship between HPWS and firm performance. These results further confirm the performance impact of HPWS and organizational coordination in PSFs. The methods employed in this research also address a call for different data points in the research timeline to facilitate causal testing in HRM research (Wright \& Gardner, 2003). Given the increasingly important role of China in the global economy and China's distinct history and culture, the study of how human resources are managed in China is critical (Gong, Law, Chang, \& Xin, 2009; Sun et al., 2007). In addition, the study of SHRM in Chinese PSFs, and the comparison of the findings for an Eastern sample (i.e. Chinese) with those from a Western sample (i.e. Irish), contributes to our understanding of SHRM in China and cross-cultural generalizability.

Fourth, we examined the impact of cultural differences in our proposed mediational model. We found that the relationship between organizational coordination and firm performance as well as in the mediation model of HPWS and firm performance via organizational coordination was stronger in Chinese PSFs than in Irish PSFs. According to Budhwar and Sparrow (2002), HRM research needs to examine how national contingency factors such as culture influence the impact of HR practices on performance. More recently, Gelfand et al. (2017) have called for future research to "understand and leverage similarities and differences in an ever-more increasingly globalized and interdependent world" (page 11). Our study answers this call by examining the role of culture on the link of HPWS with firm performance via organizational coordination. It was found that the mediating impact of organizational coordination in the relationship between HPWS and firm performance was stronger in Chinese PSFs. Such finding indicate that national culture influences the performance impact of HPWS and we encourage future research to examine how HRM influences organizational performance in different cultural contexts.

Finally, our research contributes more broadly to the literature on international HRM and its current debates. Specifically, our study adds to an accumulating body of studies on 'comparative IHRM', which involves data collection from two or more different national contexts (Cooke, Veen, \& Wood, 2017; Farndale et al., 2017). From an IHRM perspective, we examined the impact of HPWS on firm performance through organizational coordination in light of the context in which they take place (Al Ariss \& Sidani, 2016). In doing so, we contributed to one key debate "within the IHRM literature that is based on the relevance of context" (Farndale et al., 2017: 1628), i.e. the validity of the universalist versus the contextual paradigm. While the universalist paradigm advocates a 'best practice' approach for achieving strong organizational performance, the contextual paradigm (Dewettinck \& Remue, 2011) challenges the idea of a 'best practice' approach and argues that firm performance is dependent on the context in which HRM practices are being implemented. In support of the universalist paradigm, our findings showed evidence for the HPWS-firm performance link via organizational coordination in both China and Ireland. However, in support of the contextual paradigm, the effects were more pronounced in China compared to Ireland. Taken together, the results more strongly support the contextual paradigm given that the effectiveness of the same type of HR practices might differ depending on the cultural context. Companies introducing HRM policies and practice across countries and cultures (e.g., multinational companies) thus need to be mindful that their practices might not be equally effective. Further comparative studies investigating the universality versus context-dependence of HR practices are advisable.

\subsection{Practical implications}

Results from the study showed consistent support for the notion that HPWS facilitate organizational coordination which, in turn, improve firm performance in the professional service context. One challenge facing HR directors is justifying the investment in HRM. Findings 
from this study provide clear and strong empirical evidence for the effective impact of HPWS on performance in PSFs. Managers invest in human resource via high performance work systems, to improve employees' capabilities, commitment and opportunities to perform their best. The human capital developed via HPWS enhances firm capability and efficiency in coordinating tasks between teams, which, ultimately, improves firm performance.

In the analysis, we found that the relationship between organizational coordination and firm performance is stronger in Chinese PSFs than in Irish PSFs. As discussed previously, China scores higher on power distance and collectivism compared to Ireland. More coordinated work via team meetings, and the utilisationof standardized policies, processes, and procedures will therefore yield greater benefits in the Chinese context than in the Irish context. This provides helpful lessons for multinational PSF companies in Western countries who are interested in expanding to China. Although informal coordination is valuable, increased formal organizational coordination is needed in the Chinese PSF context.

For cross-cultural management, this study suggests that managers can use coordination based HR systems to improve firm performance across different countries. Although the HR practices vary between countries, their impact on organizational coordination effectiveness holds in both Eastern (China) and Western (Ireland) countries. Therefore, this study also provides managers with an effective and generalized approach to manage their employees, focused on the role of coordination mechanisms in the HR-performance relationship.

\subsection{Limitations and future research}

While this study contributes to theory and practice in many ways, it has some limitations, which we identify for future research. First of all, conceptually, HPWS focus on building and developing organization's valuable human capital via varied HR practices while organizational coordination focuses on using different mechanisms and tools to more effectively process organizational information. Despite their theoretical distinction, we acknowledge that there might be some overlap between these two concepts. For example, the correlation between the two variables in this study was $0.36(p<.01)$. Therefore, future research is needed to investigate the similarities and differences between these concepts. In addition, coordination overlaps with collaboration and is designed to ensure organization's resources are effectively used in a timely fashion (Bedwell et al., 2012). Future research is needed to distinct these concepts and to better understand the impact of HPWS on them. In relation to the HPWS measure, we adopted the systematic way to measure the HRM practices bundles. In the professional service context, all HRM practices may not work in the same way. To move HRM research forward, future research is needed to identify the key HRM practices and examine their impact on professional staff and firms. For example, work-life balance has been found as an emerging and increasingly important HRM practice in consulting firms (Noury, Gand, \& Sardas, 2017). Some other vital HRM practices which are worthy investigation include talent attraction and retainment (Gorman, 2015), as well as compensation and rewards (Adamson, Manson, \& Zakaria, 2015).

Furthermore, despite having obtained a high response rate, the sample size in both of our studies was rather small. We also focused on accounting firms, which are considered to be one classic type of PSFs. However, focusing on a single industry might limit the generalizability of our findings to other PSFs, for example, law and consulting firms. Future research is required to test our model in multiple professional service sectors. Another limitation about our sample is that the data was collected from only two countries. In particular, in the present study we proposed and tested that the impact of HPWS on firm performance via organizational coordination might be more pronounced for
Chinese compared to Irish PSFs. Although these findings have contributed to a better understanding of the role of national culture on the HPWS-firm performance link, we encourage future research to include more countries in validating this relationship. In addition, in the moderation test, we adopted two indicators for national culture, national, power distance and collectivism from Hofstede et al. (2010). Though these scores have been dominantly used by a number of studies in cross-cultural management, it is not a perfect measure of national culture as it does not capture the dynamic nature of culture in the contemporary organizations and countries studied (Taras, Steel, \& Kirkman, 2012). Future research needs to develop and adopt a more precise measure for capturing the impact of national culture.

Lastly, although this study adopted a time-lagged research design for the Irish sample, only firm performance was collected at Time 2 . This constrained exploration of causality between HPWS and organizational coordination. Future research could address this issue by collecting data on these two constructs at different time points. Finally, the data was collected from one source. In particular, the dependent variable of firm performance was based on self-report data. Thus, common method bias could be an issue. Future research would benefit from collecting data from multiple sources.

\section{Conclusion}

This study was carried out to better understand how strategic HRM influences firm performance via a cross-cultural perspective in the professional service context. Findings across two samples of professional service firms in China and Ireland revealed a key organizational process variable - effective organizational coordination between teams and projects - which was found to be a key mediator between HPWS and firm performance. In addition, we found that organizational coordination is more strongly linked to firm performance in Chinese PSFs compared to Irish PSFs indicating a relational bias. Future research therefore needs to further consider the role of culture, and the potential existence of cross-cultural differences, in the field of HRM and PSFs.

\section{Acknowledgement}

We thank the Editor Jane Frances Maley and the two anonymous reviewers for their insightful comments, constructive suggestions and great support throughout the reviewing process. We acknowledge the National Natural Science Foundation of China, Irish Research Council and Emerald/IACMR Chinese Management Research Fund for their financial support for this study. We also thank Professors Jody Hoffer Gittell, Xiangmin (Helen) Liu, and Frits Pil, participants at the Academy of Management Annual Conference 2016, as well as Ms Sarah Jane Kennedy at Dublin City University for their very helpful feedback and comments on the earlier versions of the paper. Thanks are due to Marann Byrne, Barbara Flood, Ruth Mattimoe, Mary Canning, and Orla Feeney at DCU Business School Accounting Group for their valuable advice in developing the survey in the Irish firms. Many thanks are given to Xiaoning Liang and Xuan Zhao who facilitated the data collection and input in China. Finally, we thank Mr. Diarmuid Breathnach at Chartered Accountants Ireland and Mr. Yanqi Yu at Liaoning Institute of Certified Public Accountants for their great support in conducting this cross-cultural research project, and the many HR Managers and Managing Partners who completed the surveys.

\section{References}

Adamson, M., Manson, S., Zakaria, I., 2015. Executive remuneration consultancy in the UK: Exploring a professional project through the lens of institutional work. Journal of Professions and Organization 2 (1), 19-37. https://doi.org/10.1093/jpo/jou007. Aiken, L.S., West, S.G., 1991. Multiple regression: Testing and interpreting interactions. 
Al Ariss, A., Sidani, Y., 2016. Comparative international human resource management: Future research directions. Human Resource Management Review 26 (4), 352-358. https://doi.org/10.1016/J.HRMR.2016.04.007.

Anand, N., Gardner, H.K., Morris, T., 2007. Knowledge-based innovation: Emergence and embedding of new practice areas in management consulting firms. Academy of Management Journal 50 (2), 406-428. https://doi.org/10.5465/AMJ.2007.24634457.

Armstrong, C., Flood, P.C., Guthrie, J.P., Liu, W., MacCurtain, S., Mkamwa, T., 2010. The impact of diversity and equality management on firm performance: Beyond high performance work systems. Human Resource Management 49 (6), 977-998.

Arthur, J.B., 1994. Effects of human resource systems on manufacturing performance and turnover. Academy of Management Journal 37 (3), 670-687. https://doi.org/10. $2307 / 256705$.

Barney, J., 1991. Firm resources and sustained competitive advantage. Journal of Management 17 (1), 99-120. https://doi.org/10.1177/014920639101700108.

Baron, R.M., Kenny, D.A., 1986. The moderator-mediator variable distinction in social psychological research: Conceptual, strategic, and statistical considerations. Journal of Personality and Social Psychology 51, 1173-1182, Retrieved from http://www.ncbi. nlm.nih.gov/pubmed/3806354.

Becker, B., Gerhart, B., 1996. The impact of human resource management on organizational performance: Progress and prospects. Academy of Management Journal 39 (4), 779-801. https://doi.org/10.2307/256712.

Boxall, P., Ang, S.H., Bartram, T., 2011. Analysing the "black box" of HRM: Uncovering HR goals, mediators, and outcomes in a standardized service environment. Journal of Management Studies 48 (7), 1504-1532. https://doi.org/10.1111/j.1467-6486.2010. 00973.x.

Boxall, P., Guthrie, J.P., Paauwe, J., 2016. Editorial introduction: Progressing our understanding of the mediating variables linking HRM, employee well-being and organisational performance. Human Resource Management Journal 26 (2), 103-111. https:// doi.org/10.1111/1748-8583.12104.

Brislin, R., 1980. Translation and content analysis of oral and written material. In: Handbook of cross-cultural psychology. Methodology pp. 389-444.

Budhwar, P.S., Sparrow, P.R., 2002. An integrative framework for understanding cross-national human resource management practices. Human Resource Management Review 12 (3), 377-403. https://doi.org/10.1016/S1053-4822(02)00066-9.

Chandler, A.D., 1962. Strategy and structure: Chapters in the history of the industrial enterprise. MIT Press, Cambridge, MA, https://doi.org/10.2307/3111403.

Chen, C.-J., Huang, J.-W., 2009. Strategic human resource practices and innovation performance - the mediating role of knowledge management capacity. Journal of Business Research 62 (1), 104-114. https://doi.org/10.1016/j.jbusres.2007.11.016.

Chow, I.H.s., Teo, S.T.T., Chew, I.K.H., 2013. HRM systems and firm performance: The mediation role of strategic orientation. Asia Pacific Journal of Management 30 (1), 53-72. https://doi.org/10.1007/s10490-012-9288-6.

Chuang, C.-H., Chen, S., Chuang, C.-W., 2013. Human resource management practices and organizational social capital: The role of industrial characteristics. Journal of Business Research 66 (5), 678-687. https://doi.org/10.1016/j.jbusres.2012.04.002.

Chuang, C.-H., Liao, H., 2010. Strategic human resource management in service context: Taking care of business by taking care of employees and customers. Personnel Psy chology 63 (1), 153-196. https://doi.org/10.1111/j.1744-6570.2009.01165.x.

Collins, C.J., Clark, K.D., 2003. Strategic human resource practices, top management team social networks, and firm performance: The role of human resource practices in creating organizational competitive advantage. Academy of Management Journal 46 (6), 740-751. https://doi.org/10.2307/30040665.

Collins, C.J., Smith, K.G., 2006. Knowledge exchange and combination: The role of human resource practices in the performance of high-technology firms. Academy of Management Journal 49 (3), 544-560.

Cooke, F.L., Veen, A., Wood, G., 2017. What do we know about cross-country comparative studies in HRM? A critical review of literature in the period of 2000-2014. The International Journal of Human Resource Management 28 (1), 196-233. https://doi.org/ 10.1080/09585192.2016.1245671.

Croucher, S.M., Bruno, A., McGrath, P., Adams, C., McGahan, C., Suits, A., Huckins, A., 2012. Conflict styles and high-low context cultures: A cross-cultural extension. Communication Research Reports 29 (1), 64-73. https://doi.org/10.1080/08824096. 2011.640093.

Crowston, K., 1997. A coordination theory approach to organizational process design. Organization Science 8 (2), 157-175. https://doi.org/10.1287/orsc.8.2.157.

Datta, D.K., Guthrie, J.P., Wright, P.M., 2005. Human resource management and labor productivity: Does industry matter?. Academy of Management Journal 48 (1), 135-145.

Delaney, J.T., Huselid, M.A., 1996. The impact of human resource management practices on perceptions of organizational performance. Academy of Management Journal 39 (4), 949-969.

Delery, J.E., Doty, D.H., 1996. Modes of theorizing in strategic human resource management: Tests of universalistic, contingency, and configurational performance predictions. Academy of Management Journal 39 (4), 802-835.

Dewettinck, K., Remue, J., 2011. Contextualizing HRM in comparative research: The role of the Cranet network. Human Resource Management Review 21 (1), 37-49. https:// doi.org/10.1016/J.HRMR.2010.09.010.

Faraj, S., Xiao, Y., 2006. Coordination in fast-response organizations. Management Science 52 (8), 1155-1169. https://doi.org/10.1287/mnsc.1060.0526.

Farndale, E., Raghuram, S., Gully, S., Liu, X., Phillips, J.M., Vidović, M., 2017. A vision of international HRM research. The International Journal of Human Resource Management 28 (12), 1625-1639. https://doi.org/10.1080/09585192.2017.1308416.

Farndale, E., Sanders, K., 2017. Conceptualizing HRM system strength through a cross-cultural lens. International Journal of Human Resource Management 28 (1), 132-148. https://doi.org/10.1080/09585192.2016.1239124.

Ferris, G.R., Arthur, M.M., Berkson, H.M., Kaplan, D.M., Harrell-Cook, G., Frink, D.D., 1998. Toward a social context theory of the human resource management-organization effectiveness relationship. Human Resource Management Review 8 (3), 235-264.
Fu, N., Flood, P., Bosak, J., Morris, T., O'Regan, P., 2013. Exploring the performance effect of high performance work system on service supply chain in professional service firms. Supply Chain Management: An International Journal 18 (3), 292-307.

Fu, N., Flood, P.C., Bosak, J., Morris, T., O'Regan, P., 2015. How do high performance work systems influence organizational innovation in professional service firms?. Employee Relations https://doi.org/10.1108/ER-10-2013-0155.

Fu, N., Flood, P.C., Bosak, J., Rousseau, D.M., Morris, T., O'Regan, P., 2017. High-performance work systems in professional service firms: Examining the practices-resources-uses-performance linkage. Human Resource Management 56 (2), 329-352. https://doi.org/10.1002/hrm.21767.

Galbraith, J.R., 1974. Organization design: An information processing view. Interfaces 4 (3), 28-36. https://doi.org/10.2307/25059090.

Gelfand, M., Aycan, Z., Erez, M., Leung, K., 2017. Cross-cultural industrial organizational psychology and organizational behavior: A hundred-year journey. Journal of Applied Psychology 102 (3), 514-529, Retrieved from http://psycnet.apa.org/record/ 2017-06954-001.

Gerhart, B., Wright, P.M., McMahan, G.C., Snell, S.A., 2000. Measurement error in research on human resources and firm performance: How much error is there and how does it influence effect size estimates?. Personnel Psychology 53 (4), 803-834. https: //doi.org/10.1111/j.1744-6570.2000.tb02418.x.

Gittell, J.H., Seidner, R., Wimbush, J., 2010. A relational model of how high-performance work systems work. Organization Science 21 (2), 490-506.

Gong, Y., Law, K.S., Chang, S., Xin, K.R., 2009. Human resources management and firm performance: The differential role of managerial affective and continuance commitment. Journal of Applied Psychology 94 (1), 263-275. https://doi.org/10.1037/ a0013116.

Gorman, E.H., 2015. Getting ahead in professional organizations: Individual qualities, socioeconomic background and organizational context. Journal of Professions and Organization 2 (2), 122-147. https://doi.org/10.1093/jpo/jov001.

Guthrie, J.P., 2001. High-involvement work practices, turnover, and productivity: Evidence from New Zealand. Academy of Management Journal 44 (1), 180-190.

Hall, E.T., 1976. Beyond culture. Anchor Books, Garden City, NY.

Harris, L.C., Ogbonna, E., 2001. Strategic human resource management, market orientation, and organizational performance. Journal of Business Research 51 (2), 157-166. https://doi.org/10.1016/S0148-2963(99)00057-0.

Hauff, S., Richter, N.F., Tressin, T., 2015. Situational job characteristics and job satisfac tion: The moderating role of national culture. International Business Review 24 (4), 710-723. https://doi.org/10.1016/j.ibusrev.2015.01.003.

Hayes, A., 2013. Introduction to mediation, moderation, and conditional process analysis Guilford, New York, NY, 3-4, (http://doi.org/978-1-60918-230-4).

Hayes, A.F., 2009. Beyond Baron and Kenny: Statistical mediation analysis in the new millennium. Communication Monographs 76 (4), 408-420. https://doi.org/10.1080/ 03637750903310360 .

Hitt, M.A., Bierman, L., Shimizu, K., Kochhar, R., 2001. Direct and moderating effects of human capital on strategy and performance in professional service firms: A resource-based perspective. Academy of Management Journal 44 (1), 13-28. https:// doi.org/10.2307/3069334.

Hofstede, G., Hofstede, G.J., Minkov, M., 2010. Cultures and organizations, software of the mind: Intercultural cooperation and its importance for survival, 3rd edition McGraw-Hill, New York, https://doi.org/10.1016/j.cede.2012.04.002.

Huselid, M.A., 1995. The impact of human resource management practices on turnover productivity, and corporate financial performance. Academy of Management Journal 38 (3), 635-672.

Jiang, K., Lepak, D.P., Hu, J., Baer, J.C., 2012. How does human resource managemen influence organizational outcomes? A meta-analytic investigation of mediating mech anisms. Academy of Management Journal 55 (6), 1264-1294. https://doi.org/10. 5465/amj.2011.0088.

Kittler, M.G., Rygl, D., Mackinnon, A., 2011. Special review article: Beyond culture or beyond control? Reviewing the use of Hall's high-/low-context concept. International Journal of Cross Cultural Management 11 (1), 63-82. https://doi.org/10.1177/ 1470595811398797.

Kraut, R.E., Streeter, L.A., 1995. Coordination in software development. Communications of the ACM 38 (3), 69-81. https://doi.org/10.1145/203330.203345.

Liao, H., Toya, K., Lepak, D.P., Hong, Y., 2009. Do they see eye to eye? Management and employee perspectives of high-performance work systems and influence processes on service quality. Journal of Applied Psychology 94 (2), 371-391.

Maister, D.H., 1993. Managing the professional service firm. Free Press, New York.

Malone, T.W., Crowston, K., 1994. The interdisciplinary study of coordination. ACM Computing Surveys 26 (1), 87-119. https://doi.org/10.1145/174666.174668.

March, J., Simon, H., 1958. Organizations. John Wiley, New York, Retrieved from http:// psycnet.apa.org/record/1958-15040-000.

Mintzberg, H., 1979. The structuring of organizations: A synthesis of the research. Prentice-Hall.

Muller, D., Judd, C.M., Yzerbyt, V.Y., 2005. When moderation is mediated and mediation is moderated. Journal of Personality and Social Psychology 89 (6), 852-863. https:// doi.org/10.1037/0022-3514.89.6.852.

Nahapiet, J., Ghoshal, S., 1998. . Academy of Management Review 23 (2), 242-266. https: //doi.org/10.2307/259373

Noury, L., Gand, S., Sardas, J.-C., 2017. Tackling the work-life balance challenge in professional service firms: The impact of projects, organizing, and service characteristics. Journal of Professions and Organization 4 (2), 149-178. https://doi.org/10.1093/jpo/ jow010.

Okhuysen, G.A., Bechky, B.A., 2009. Coordination in organizations. Academy of Management Annals 3 (1), 463-502. https://doi.org/10.1080/19416520903047533.

Piening, E.P., Baluch, A.M., Salge, T.O., 2013. The relationship between employees' perceptions of human resource systems and organizational performance: Examining mediating mechanisms and temporal dynamics. The Journal of Applied Psychology 98 (6), 926-947. https://doi.org/10.1037/a0033925. 
Preacher, K.J., Rucker, D.D., Hayes, A.F., 2007. Addressing moderated mediation hypotheses: Theory, methods, and prescriptions. Multivariate Behavioral Research 42 (1), 185-227. https://doi.org/10.1080/00273170701341316.

Skjølsvik, T., Pemer, F., Løwendahl, B.R., 2017. Strategic management of professional service firms: Reviewing ABS journals and identifying key research themes. Journal of Professions and Organization 4 (2), 203-239. https://doi.org/10.1093/jpo/jox005.

Sun, L., Aryee, S., Law, K.S., 2007. High-performance human resource practices, citizenship behaviour and organizational performance: $\{A\}$ relational perspective. Academy of Management Journal 50, 558-577.

Takeuchi, R., Lepak, D.P., Wang, H.C., Takeuchi, K., 2007. An empirical examination of the mechanisms mediating between high-performance work systems and the performance of \{Japanese\} organizations. Journal of Applied Psychology 92 (4), 1069-1083.

Taras, V., Steel, P., Kirkman, B.L., 2012. Improving national cultural indices using a longitudinal meta-analysis of Hofstede's dimensions. Journal of World Business 47 (3), 329-341. https://doi.org/10.1016/j.jwb.2011.05.001.

von Nordenflycht, A., 2010. What is a professional service firm? Toward a theory and taxonomy of knowledge intensive firms. Academy of Management Review 35 (1), 155-174.

Wall, T., Michie, J., Patterson, M., Wood, S., Sheehan, M., Clegg, C., West, M., 2004. On the validity of subjective measures of. Personnel Psychology 57 (1), 95-118. https:// doi.org/10.1111/j.1744-6570.2004.tb02485.x.

Wright, P.M., Gardner, T.M., 2003. The human resource - Firm performance relationship: Methodological and theoretical challenges. In: Holman, D., Wall, T.D., Clegg, C.W., Sparrow, P., Howard, A. (Eds.), The new workplace. John Wiley \& Sons, Ltd, pp. $311-328$

Na Fu is an Associate Professor in Human Resource Management at Trinity Business School, Trinity College Dublin, the University of Dublin. She received her BA from Northeastern University (China) and $\mathrm{PhD}$ from Dublin City University. Dr Fu is a multi-award winner from the Academy of Management, Irish Academy of Management, Irish Re- search Council and Emerald. Her work has been published in Journal of Management, Human Resource Management, Human Resource Management Journal, Human Relations, and International Journal of Human Resource Management among others.

Janine Bosak is an Associate Professor in Work and Organizational Psychology at DCU Business School, Director of Doctoral Studies, and Director of Research of the Leadership and Talent Institute (LTI) at DCU. Janine's work has been published in Personality and Social Psychology Bulletin, the British Journal of Management, the British Journal of Social Psychology, and International Journal of Human Resource Management.

Patrick C Flood is Professor of Organizational Behavior at Dublin City University. He received his $\mathrm{PhD}$ from the London School of Economics and is a Fellow of the Academy of Social Sciences. He has published extensively including Journal of Management, Journal of Organizational and Occupational Psychology, Human Relations, and the Strategic Management Journal.

Qinhai Ma is Professor of Service Management and the Dean of the School of Business Administration at Northeastern University (China). He achieved his PhD from Hong Kong University of Science \& Technology. He has published in Technovation, Business Process Management Journal, and International Journal of Service Technology and Management. 